\title{
Biological Evaluation of the Effect of Galvanic Coupling Intrabody Communication on Human Skin Fibroblast Cells
}

\author{
Shi Lin, ${ }^{1,2}$ Yue-Ming Gao, ${ }^{1,2}$ Juan Cai, ${ }^{1,2}$ Željka Lučev Vasić, ${ }^{3}$ Mang-I Vai, ${ }^{2,4,5}$ Min Du, \\ Mario Cifrek, ${ }^{3}$ and Sio-Hang Pun ${ }^{4}$ \\ ${ }^{1}$ College of Physics and Information Engineering, Fuzhou University, Fuzhou, China \\ ${ }^{2}$ Key Lab of Medical Instrumentation \& Pharmaceutical Technology of Fujian Province, Fuzhou, China \\ ${ }^{3}$ Faculty of Electrical Engineering and Computing, University of Zagreb, Zagreb, Croatia \\ ${ }^{4}$ State Key Laboratory of Analog and Mixed-Signal VLSI, University of Macau, Macau, China \\ ${ }^{5}$ Department of Electrical and Computer Engineering, Faculty of Science and Technology, University of Macau, Macau, China \\ ${ }^{6}$ Key Lab of Eco-Industrial Green Technology of Fujian Province, Nanping, China
}

Correspondence should be addressed to Yue-Ming Gao; fzugym@163.com

Received 26 May 2017; Accepted 6 August 2017; Published 14 September 2017

Academic Editor: Pierre-Martin Tardif

Copyright (C) 2017 Shi Lin et al. This is an open access article distributed under the Creative Commons Attribution License, which permits unrestricted use, distribution, and reproduction in any medium, provided the original work is properly cited.

Intrabody communication (IBC) is an effective way to connect various kinds of wearable devices attached on or under the surface of the body, but it is important to quantitatively evaluate the biological effects of the IBC signal on the human body before its further application. The research described in this paper analyzed the responses of HSF (human skin fibroblast) cells exposed to IBC electrical signals. A galvanic coupling IBC signal transmitting system was designed to expose the experimental samples with different amplitudes (from $0 \mathrm{~V}$ to $6 \mathrm{~V}$ or $0 \mathrm{~mA}$ to $4 \mathrm{~mA}$ ), different frequencies (from $10 \mathrm{kHz}$ to $1 \mathrm{MHz}$ ), and different duration times $(12 \mathrm{~h}$ and $24 \mathrm{~h})$. The control groups were unexcited. Cell morphology and activity were evaluated with inverted microscope and MTT assays. The cell survival rates of all the experiment groups were in the range of $90 \%$ to $110 \%$. Then, the data was analyzed by $t$-tests to assess whether there were statistically significant differences. The results showed that $p$ values were greater than 0.05 , so there were no significant differences between the experimental and control groups. Therefore, it can be concluded that the IBC signals do not have a significant effect on HSF cells.

\section{Introduction}

Wearable sensors, which can continuously monitor human activities and physiological signals, can be attached on or under the surface of the human body. Body Area Network (BAN) attempts to provide a suitable wireless protocol with low power consumption, high reliability, and lower emissions to collect the information from wearable sensors to evaluate the human health status anytime and anywhere. Unlike common wireless technology, intrabody communication (IBC) uses human tissue as a transmission medium $[1,2]$, so it has the advantages of less path loss, high confidentiality, and high efficiency [3]. Because of this, it has become a potential communication technology for BAN that is standardized in IEEE 802.15.6 [4].
Recent IBC technology research has focused on physical modeling of human channels [5-7], in vivo measurements $[3,8]$, and the implement of transceivers [9-11]. Because the human body is the transmitting medium for IBC [12], especially for the galvanic coupling type of IBC, a biological safety evaluation of the effect of the IBC electrical signal on the human body is essential. However, the safety issue of IBC is still an unknown area. The common evaluation methods include numerical methods for evaluating the electromagnetic field, phantom experiments, and even biological experiments. The numerical method can reveal the propagation mechanism of the electrical signal within or around the human body $[13,14]$. But it is still unclear how to create a more precise human abstract model. For the phantom model, a saline solution or other conductive 
material represents the dielectric properties of human body for measurements of the electrical parameters [15-17], but it is difficult to get a phantom material with dielectric properties that are similar to human tissues for a wide frequency range. The results of these two methods are just approximations, and errors are difficult to eliminate.

Biological experiments done in vivo on living individuals, such as human or animals, lead to a number of complex ethical issues. But the subjects of in vitro experiments were usually the cells, and there is significant advantage that the process can be rigorously controlled.

In the experiments described in this paper, instead of doing tests on humans directly, human skin fibroblast (HSF) cells were cultivated in vitro to evaluate the effect of IBC electrical signals. A galvanic coupling IBC system was designed to expose the HSF cells to different strengths, frequencies, and duration times of IBC electrical signals. The morphology of the cells was observed by an inverted optical microscope, and the survival rate of experimental groups was determined by MTT assays. Studying the biological effects of galvanic coupling IBC weak signals on HSF cells can provide information about the impact of IBC signals on the human body.

Section 2 describes the experimental materials and methods. In Section 3, the experimental results for different intensities, frequencies, and times of exposure to IBC signals are analyzed and discussed. Finally, Section 4 describes our conclusions.

\section{Materials and Methods}

2.1. Experimental Object. When electrical signals of human body communication inject into the human body, they enter the skin first. After passing through the skin, the strength of the signals declines rapidly [13], so the skin suffers the strongest electrical signal. For this reason, HSF cells that cultured in vitro were selected as the experimental objects. The cells were purchased from Beijing Dingguo Biotechnology Co., Ltd.

There were two groups in our research, the experimental group that received the IBC signal and a control group that did not.

2.2. Reagents and Instruments. The main reagents were Dulbecco's modified Eagle's medium (DMEM), high glucose medium (Hyclone, Logan, UT, USA), fetal bovine serum (FBS) (Hyclone, Logan, UT, USA), trypsin (Amresco, OH, USA), and dimethyl sulfoxide (DMSO) (Sigma, St. Louis, USA). The main instruments were Petri dishes, pipettes, an inverted optical microscope (XDS-1B, Optoelectronic Instrument Co., Ltd, Chongqing, China), a $\mathrm{CO}_{2}$ incubator (NUAIR 550, Nuaire, Inc., Minnesota, USA), and a microplate reader (SH-1000, Corona Electric Co., Ltd., Higashi-Ishikawa, Japan).

2.3. HSF Cells Culture. HFS cells were cultured in DMEM, which contained $10 \%$ fetal bovine serum (FES) and $1 \%$ antibiotic (penicillin and streptomycin) [18]. The cultured cells were incubated in a $\mathrm{CO}_{2}$ incubator $\left(37^{\circ} \mathrm{C}, 95 \%\right.$ air + $5 \% \mathrm{CO}_{2}$ ) [19]. When the cell fusion was up to $80 \%$, the digestion of trypsin separated cells into a suspension. The suspension was transferred into different 6-well culture dish with a concentration of $2 \times 10^{5}$ cells $/ \mathrm{mL}$.

2.4. Groups Setting. The experiment began when the adherent cells covered $70 \%$ to $80 \%$ of the area of a single well in the 6-well culture dish. First, the DMEM medium was carefully sucked out. Second, a PBS buffer was added to remove residual DMEM, dead cells, and senescent cells. Third, the wastewater was sucked out and discarded. Finally, $2 \mathrm{~mL}$ of none-FBS culture medium was added to each well to avoid the effect of serum on promoting cell proliferation.

The procedure for the control group was the same as for the experimental group, except that the stress of IBC signal on the control group was zero. In order to ensure accuracy and reliability for the experimental data, two experimental groups and two control groups were used for every experiment. The cells for each experiment group were subjected to IBC signals by a pair of electrodes. The electrodes were sterilized with $75 \%$ ethanol and irradiated for $30 \mathrm{~min}$ with UV light before each experiment [20]. To ensure the consistency of the initial cells number, the subcultured cells were collected and divided into experimental group and the control group averagely.

2.5. The Establishment of the IBC Excitation System. The excitation system for the galvanic coupling IBC included an excitation source that can generate characteristic IBC signals, the HSF cells culture environment, and the electrodes that inject the electrical signal into cells. This system is one kind of current excitation model, so the electrodes should be in direct contact with the culture solution. In order to prevent electrochemical reactions at the electrodes and in the culture medium, which may produce harmful substances, an inert metal platinum electrode was used for the electrical conductor [21]. The needle ends of the platinum electrodes were bent by $90^{\circ}$ and their length was about $1.5 \mathrm{~cm}$ which can be fully contacted in the liquid. And the transceiver electrodes were placed in parallel; distance between them was $1 \mathrm{~cm}$. The system diagram is shown in Figure 1(a), and the real photo of the experimental apparatus is shown in Figure 1(b).

In the process of IBC, there is a high demand for an AC source for creating signals to the human body, and the output signal must have small waveform distortion and high amplitude stability. The output of the AC signal source or chip is commonly a voltage signal. In order to produce a constant AC current signal, we needed to set up a V/I convert circuit to convert the input voltage signal into a corresponding current signal. The output current was then stabilized by feedback [22]. See Figure 2.

AD844 shown in Figure 2 is a high speed, high bandwidth, current mirror device with a current feedback operational amplifier that can achieve voltage convert [23]. Because the input resistance of AD844 is not zero, it could cause an error in the first-order gain accuracy. Therefore, we needed an OP37 operational amplifier, which includes high speed, low noise, and low temperature drift, as an input buffer to 


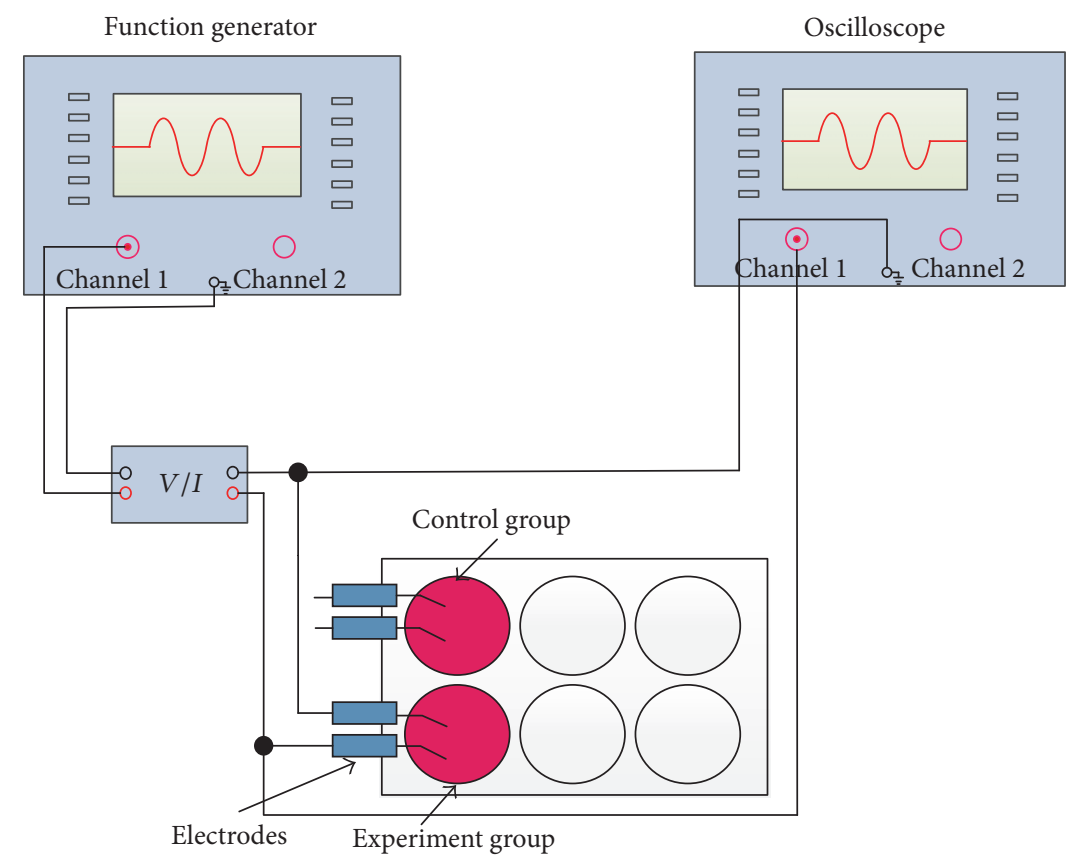

(a) The system diagram of experiment

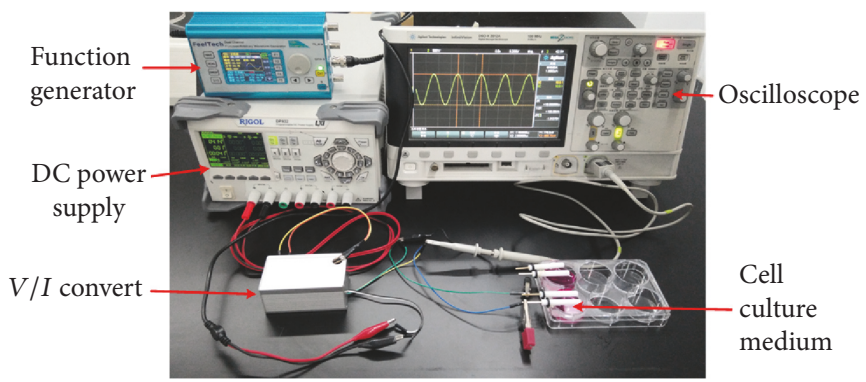

(b) The real photo of the experimental apparatus

FIGURE 1: The experimental diagram of human skin fibroblast cells.

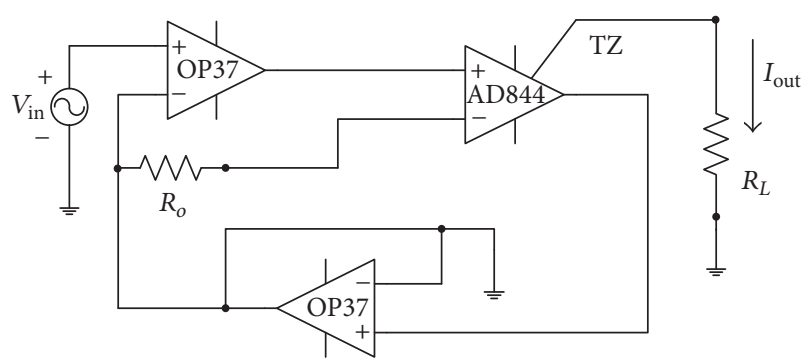

FIgURE 2: AC constant current source schematic.

eliminate the influence on the output current of the inverted input resistance of the current feedback operational amplifier. The load was connected to the TZ pin of the AD844 (5 pin) through the isolation capacitor. A DC capacitor in the system can cause stability problems; so to improve system stability, a DC feedback circuit was added to output pin 6 of the AD844 to ensure that the DC voltage was zero before passing through the DC capacitor.
The constant current module was made according to schematic diagram in Figure 2. The performance of the AC constant current source module was tested for amplitude characteristics, load capacity, and system stability.

2.5.1. Amplitude Characteristics. Table 1 shows the relationships between output current and input voltage for frequencies of $10 \mathrm{kHz}, 400 \mathrm{kHz}$, and $800 \mathrm{kHz}$ with the input voltage increasing from $0.5 \mathrm{~V}$ to $2 \mathrm{~V}$. It can be seen that there is a linear increase in output current as the input voltage increases at different frequencies. The $V / I$ convert characteristics of the $\mathrm{AC}$ constant current source are good at different frequencies. In addition, the absolute error of output current at different frequencies is less than $0.073 \mathrm{~mA}$ for all of the voltages tested. The maximum relative error is $2 \%$ for the input voltage of $2 \mathrm{~V}$. Therefore, the tests show that the AC constant current source has good amplitude characteristics.

2.5.2. Load Capacity. The system shown in Figure 1 was used to test the resistance of the cell culture medium. The settings 
TABLE 1: The relationship of input voltage and output current at different frequency.

\begin{tabular}{lcccc}
\hline$V_{\text {in }}(\mathrm{V})$ & & $I_{\text {out }}(\mathrm{mA})$ & & \\
\hline 0.5 & $10 \mathrm{kHz}$ & $400 \mathrm{kHz}$ & $800 \mathrm{kHz}$ & 0.873 \\
1 & 0.855 & 0.847 & 1.834 & 0.026 \\
1.5 & 1.795 & 1.779 & 2.833 & 0.072 \\
2 & 2.782 & 2.761 & 3.727 & 0.073 \\
\hline
\end{tabular}

for the excitation source input signal were $\mathrm{V}_{\mathrm{p}-\mathrm{p}}=1 \mathrm{~V}$ and $f$ $=40 \mathrm{kHz}$. A fixed value resistor, $R$, was added between the signal terminal and the negative electrode. The total signal of the fixed value resistance and the cell, $V_{\mathrm{T}}$, was measured, and the voltage of the fixed value resistance, $V_{\mathrm{R}}$, was obtained. Then the cell culture medium resistance, $R_{\mathrm{L}}$, was calculated from (1). After repeated experiments, the average resistance value of the cell culture medium was determined to be 619.14 $\pm 29.48 \Omega$.

$$
R=\frac{V_{\mathrm{T}}-V_{\mathrm{R}}}{V_{\mathrm{R}}} R_{\mathrm{L}}
$$

The load performance of AC constant current source was evaluated by accessing a variable resistor range from $0 \Omega$ to $1 \mathrm{k} \Omega$ on the output terminal which changed in intervals of $200 \Omega$. Then the output current was measured with the AC constant current source output signals of frequencies range from $10 \mathrm{kHz}$ to $1 \mathrm{MHz}$, and the input voltage increasing from $0.5 \mathrm{~V}$ to $2 \mathrm{~V}$. The results showed that different load values would lead to a slight deviation of output current. However, the maximum absolute error is less than $0.1 \mathrm{~mA}$. Therefore, it can be considered that the AC constant current source has good performance under required load range.

2.5.3. System Stability Test. The time for the system stability test was 24 hours. In the first 6 hours, the performance of circuit was monitored by oscilloscope at 30-minute intervals. Then, the system was observed at 1-hour intervals for 6 hours. After this, the system was tested every 12 hours. After many days, the results showed that the output current deviations for different frequencies and signal intensities were not greater than $0.05 \mathrm{~mA}$. The results confirmed that the system can operate steadily for 24 hours.

2.6. Methods. The galvanic coupling IBC system described in Section 2.5 is able to output weak IBC signals to excite the HFS cells of the experimental group in vitro. The frequency of the galvanic coupling IBC signal ranged from $10 \mathrm{kHz}$ to $1 \mathrm{MHz}$, the current intensity range was $1 \mathrm{~mA}$ to $4 \mathrm{~mA}$, and the voltage intensity range was $1 \mathrm{~V}$ to $6 \mathrm{~V}$. The distance between two transceiver electrodes mentioned in the Section 2.5 was $1 \mathrm{~cm}$. While taking voltage as the excitation signal, the electric field intensity ranged from $1 \mathrm{~V} / \mathrm{cm}$ to $6 \mathrm{~V} / \mathrm{cm}$. HSF cells have a high metabolic rate. In order to prevent the effect of contact inhibition on the experimental results, the cells were cultured in vitro according to the method described in Section 2.3. The times for the experiments were 12 hours and 24 hours, and each experiment was repeated five times.
Directing an electrical signal with a certain intensity and frequency at an organism will affect its physiological state [24]. Yuan et al. [25] studied the effects of electrical stimulation on meniscus cell. The results showed that $2 \mathrm{~ms}$ pulses repeated at $10 \mathrm{~Hz}$ with an electric field of $3 \mathrm{~V} / \mathrm{cm}$ enhanced meniscus cell migration. The maximum rate of cell migration, illustrated in Sun et al., [26], was achieved by $0.1 \mathrm{~V} / \mathrm{cm}$ of electrical stimulus. Application of larger electrical stimulus strengths did not increase the rate of induced cell migration. Moreover, biphasic electrical currents promote both proliferation and neuronal differentiation of fetal neural stem cells [27]. Electrical stimulation can promote or inhibit cell proliferation, induced apoptosis, or affect differentiation. Cell proliferation is a basic biological component of the metabolic process. The external stimulus may cause the cells to proliferate faster or slower. Therefore, after the cells were exposed to the IBC signal, an MTT assay was done to detect cell activity of the experimental group and the control group. The survival rates of the experiment groups were used to evaluate the effect of IBC electrical signals on the HSF cells. The detection principle of the MTT assay is that succinate dehydrogenase in mitochondria of living cells can reduce MTT to water-insoluble formazan, which is a blueviolet crystalline substance. Dead cells have no such function. DMSO dissolves formazan [28], and the solution's absorbance (described as OD) was determined by ELISA. A higher OD value indicates a greater number of living cells.

Cell viability can be calculated using (2). Generally, a survival rate within the range of $90 \%$ to $110 \%$ suggests an insignificant effect of external excitation on cells. A survival rate above $110 \%$ suggests that the exposure to the signal promotes growth of cells, and a survival rate less than $90 \%$ suggests that exposure to the signal inhibits growth.

$$
\text { Survival rate }=\frac{\mathrm{OD}_{\text {experiment }}}{\mathrm{OD}_{\text {control }}} \times 100 \% \text {. }
$$

\section{Results and Discussion}

3.1. Morphological Observation. The morphologies of the HSF cells with and without signal exposure were observed by inverted optical microscope. As shown in Figure 3(a), and the magnification of inverted optical microscope is $\times 10$. Figure 3(b) shows when cells are inoculated, HSF cells present a spherical shape and small size and are suspended in the cell culture medium. As the cells were cultured, they began to adhere and stretch out the parapodium. Most of the adherent cells were fusiform fibroblasts with oval nuclei. Then the number of cells increased rapidly. Figure 3(c) shows that the 


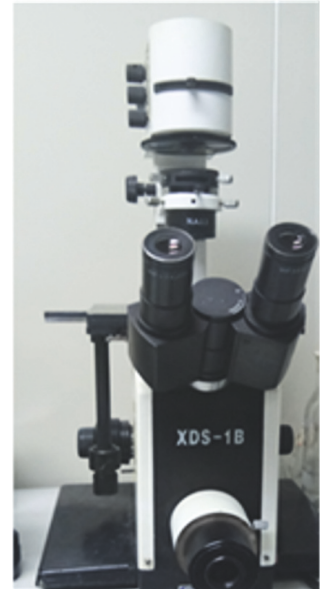

(a) Inverted optical microscope

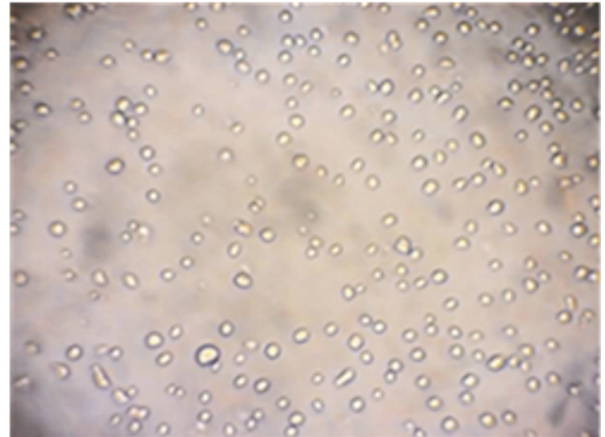

(b) Inoculated HSF cell morphology

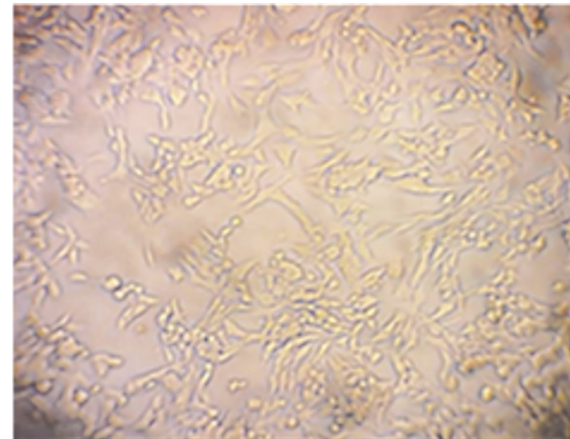

(c) After culturing $24 \mathrm{~h}$

FIGURE 3: HSF cell morphology under inverted microscope.

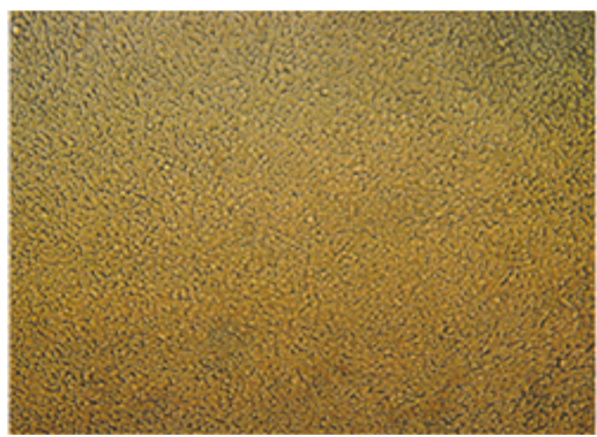

(a) Cell morphology of experiment group

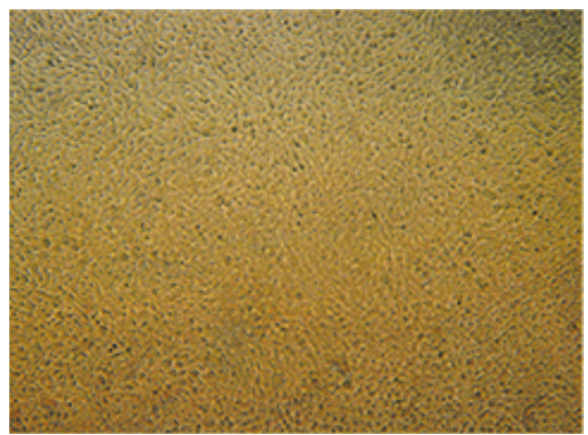

(b) Cell morphology of control group

FIGURE 4: The morphology of HSF cells in the experimental group and control group.

shapes of the HSF cells were spindle-shaped, mixed with irregular-shaped. With increased culture time, the decrease in culture medium in the culture dish and the limited culture space inhibit HSF cell growth.

The HSF cells cover $70 \% \sim 80 \%$ of single pore area of 6-well culture dish. Figure 4(a) shows that, after 24 hours of IBC electrical excitation, the HSF cells were very tightly packed. The number of cells increased significantly compared to before excitation. The medium became yellow with dead cells floating in the liquid. However, Figure 4 shows that there was no visible difference in morphology and number of experiment group compared to the control group.

\subsection{Detection of Cell Viability. After IBC electrical excitation,} the mediums of the experimental and control groups were absorbed, and MTT was added to the culture. The cells in MTT solution were incubated for 4 hours to allow for sufficient reaction. Then the HSF cells were observed under the inverted microscope, and Figure 5 shows the state of the cells. Succinate dehydrogenase in the mitochondria of living cells and MTT reacted to form a blue-violet formazan, but this reaction does not take place in the dead cells. Therefore, the concentration of generated formazan reflects the number of living cells. DMSO was added to dissolve the formazan, and the solution appeared purple. The darker the solution, the greater the number of living cells. The quantitative analysis of the solution was performed by a microplate reader, and the results were expressed by absorbance values.

There were four groups for each experiment, divided into two control groups and two experimental groups. Table 1 shows the experimental results for different signal intensities, frequencies, and excitation times. For example, a group described as $(1 \mathrm{~mA}, 10 \mathrm{kHz}, 12 \mathrm{~h})$ had a signal intensity of $1 \mathrm{~mA}$, a frequency of $10 \mathrm{kHz}$, and an excitation time of 12 hours. The control groups were unexcited. Each group was divided into 10 subgroups. For each subgroup, the formazan was dissolved fully in DMSO and was transferred to 10 holes in a 96 -hole plate. The volume of each hole was $100 \mu \mathrm{L}$. The solutions were shaken at a speed of $100 \mathrm{rpm}$ at $15^{\circ} \mathrm{C}$. To detect solution absorbance, the wavelength of the microplate reader was set at $570 \mathrm{~nm}$. The results were exported to Excel.

Posttreatment, the differences between the two experiment groups and between the two control groups were 


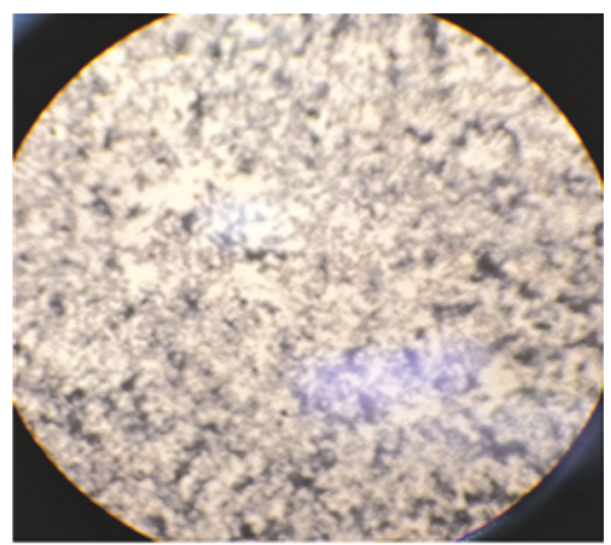

FIGURE 5: The reaction of living cells and MTT to generate formazan.

TABLE 2: Analysis of experimental results.

\begin{tabular}{lccc}
\hline Group & Survival rate & $p$ & Significant difference \\
\hline$(1 \mathrm{~mA}, 10 \mathrm{kHz}, 12 \mathrm{~h})$ & $99.8 \%$ & 0.820 & Not significant \\
$(1 \mathrm{~mA}, 1 \mathrm{MHz}, 12 \mathrm{~h})$ & $100.1 \%$ & 0.345 & Not significant \\
$(1 \mathrm{~mA}, 1 \mathrm{MHz}, 24 \mathrm{~h})$ & $98.7 \%$ & 0.234 & Not significant \\
$(4 \mathrm{~mA}, 10 \mathrm{kHz}, 12 \mathrm{~h})$ & $98.9 \%$ & 0.428 & Not significant \\
$(4 \mathrm{~mA}, 1 \mathrm{MHz}, 12 \mathrm{~h})$ & $97.0 \%$ & 0.344 & Not significant \\
$(4 \mathrm{~mA}, 1 \mathrm{MHz}, 24 \mathrm{~h})$ & $94.9 \%$ & 0.296 & Not significant \\
$(1 \mathrm{~V}, 10 \mathrm{kHz}, 12 \mathrm{~h})$ & $99.1 \%$ & 0.324 & Not significant \\
$(1 \mathrm{~V}, 1 \mathrm{MHz}, 12 \mathrm{~h})$ & $98.5 \%$ & 0.299 & Not significant \\
$(1 \mathrm{~V}, 1 \mathrm{MHz}, 24 \mathrm{~h})$ & $98.6 \%$ & 0.296 & Not significant \\
$(6 \mathrm{~V}, 10 \mathrm{kHz}, 12 \mathrm{~h})$ & $93.1 \%$ & 0.145 & Not significant \\
$(6 \mathrm{~V}, 1 \mathrm{MHz}, 12 \mathrm{~h})$ & $92.5 \%$ & 0.096 & Not significant \\
$(6 \mathrm{~V}, 1 \mathrm{MHz}, 24 \mathrm{~h})$ & $91.6 \%$ & 0.077 & Not significant \\
\hline
\end{tabular}

evaluated and found not to be significant. Otherwise, this experiment is invalid. The OD values of used for analysis of the experimental and control groups were the mean values of the 10 subgroups. The survival rate was calculated by (1). Finally, the difference between the experimental group and the control group was analyzed by IBM SPSS Statistics V22 (International Business Machines Corporation, Armonk, USA), using $t$-tests to assess whether there were significant differences. The significance level is determined as $p<0.05$ for the statistical analyses. Table 2 shows the median $p$ values for different signal intensities, frequencies, and excitation times.

Table 2 shows that, with an increase of signal intensity and frequency, the survival rate of HSF cells decreases to some extent. For example, the survival rate was $98.7 \%$ for group $(1 \mathrm{~mA}, 1 \mathrm{MHz}, 24 \mathrm{~h})$, but it decreased to $94.9 \%$ for the higher signal intensity for group ( $4 \mathrm{~mA}, 1 \mathrm{MHz}, 24 \mathrm{~h}$ ). The survival rate was $98.9 \%$ for group $(4 \mathrm{~mA}, 10 \mathrm{kHz}, 12 \mathrm{~h})$, but it decreased to $97.0 \%$ for the higher signal frequency group $(4 \mathrm{~mA}, 1 \mathrm{MHz}$, $12 \mathrm{~h}$ ). In addition, the survival rate of HSF cells decreased slightly with increased excitation time. For example, the survival rate for group ( $4 \mathrm{~mA}, 1 \mathrm{MHz}, 12 \mathrm{~h}$ ) was $97.0 \%$, but it decreased to $94.9 \%$ for group ( $4 \mathrm{~mA}, 1 \mathrm{MHz}, 24 \mathrm{~h}$ ), which had a longer excitation time. Therefore, the intensity, frequency, and time of exposure to galvanic coupling IBC excitation signals are all factors that affect HSF cells.

\section{Conclusion}

In order to quantitatively evaluate the biological effects of IBC signals on the human body, a galvanic coupling IBC signal transmitting system was designed to excite HSF cells with different amplitudes, frequencies, and duration times.

First, the morphologies of HSF cells at different times were observed under an inverted microscope. The HFS cells adhered to the culture plate after a period time. It was found that there was no visible difference between the experimental group and the control group after exposure to IBC electrical signals. Repeated experiments were carried out to ensure the accuracy of the results. Next, a microplate reader and MTT assays were used to detect the survival rate of the cells. The experimental data show that the use of different intensities and frequencies of weak IBC electrical signals on HSF cells for long times led to cell survival rates for all 
the experiments in the range from $90 \%$ to $110 \%$. Finally, the data for each experimental group and the control group were analyzed by $t$-tests. The $p$ values of all the tests were more than 0.05 , indicating that there were no statistically significant differences between all the experimental groups and the control groups. Therefore, our procedure provides quantitative evidence that weak IBC signals do not affect the activity of human HSF cells. Our procedure could provide an experimental basis for further exploration of the influence of IBC electrical signals on the human body.

\section{Conflicts of Interest}

The authors declare that they have no conflicts of interest.

\section{Acknowledgments}

This research was made possible by the National Natural Science Foundation of China U150525 and the Project of Chinese Ministry of Science and Technology 2016YFE0122700.

\section{References}

[1] T. G. Zimmerman, "Personal area networks: Near-field intrabody communication," IBM Systems Journal, vol. 35, no. 3-4, pp. 609-617, 1996.

[2] M. A. Callejon, D. Naranjo-Hernandez, J. Reina-Tosina, and L. M. Roa, "A comprehensive study into intrabody communication measurements," IEEE Transactions on Instrumentation and Measurement, vol. 62, no. 9, pp. 2446-2455, 2013.

[3] Y.-M. Gao, Z.-M. Wu, S.-H. Pun, P.-U. Mak, M.-I. Vai, and M. Du, "A novel field-circuit FEM modeling and channel gain estimation for galvanic coupling real IBC measurements," Sensors (Switzerland), vol. 16, no. 4, article 471, 2016.

[4] K. Ito and Y. Hotta, "Signal Path Loss Simulation of Human Arm for Galvanic Coupling Intra-Body Communication Using Circuit and Finite Element Method Models," in Proceedings of the 2015 12th IEEE International Symposium on Autonomous Decentralized Systems, ISADS 2015, pp. 230-235, twn, March 2015.

[5] K. Zhang, Q. Hao, Y. Song, J. Wang, R. Huang, and Y. Liu, "Modeling and characterization of the implant intra-body communication based on capacitive coupling using a transfer function method," Sensors (Switzerland), vol. 14, no. 1, pp. 17401756, 2014.

[6] M. Swaminathan, F. S. Cabrera, J. S. Pujol, U. Muncuk, G. Schirner, and K. R. Chowdhury, "Multi-Path Model and Sensitivity Analysis for Galvanic Coupled Intra-Body Communication Through Layered Tissue," IEEE Transactions on Biomedical Circuits and Systems, vol. 10, no. 2, pp. 339-351, 2016.

[7] B. Kibret, M. Seyedi, D. T. H. Lai, and M. Faulkner, "Investigation of galvanic-coupled intrabody communication using the human body circuit model," IEEE Journal of Biomedical and Health Informatics, vol. 18, no. 4, pp. 1196-1206, 2014.

[8] M. A. Callejón, D. Naranjo, L. J. Reina-Tosina, and L. M. Roa, "A first approach to the harmonization of intrabody communications measurements," in Proceedings of the World Congress on Medical Physics and Biomedical Engineering, pp. 704-707, Beijing, China, May 2012.
[9] Ž. Lučev, I. Krois, and M. Cifrek, "Intrabody communication in biotelemetry," Lecture Notes in Electrical Engineering, vol. 75, pp. 351-368, 2010.

[10] X. M. Chen, S. H. Pun, Z. T. Wang, P.-U. Mak, and M. I. Vai, "Quasi-static field modeling with bone and joint effects in intrabody communication," in Proceedings of the 8th International Conference on Information, Communications and Signal Processing, ICICS 2011, sgp, December 2011.

[11] S. H. Pun, Y. M. Gao, P. U. Mak, M. I. Vai, and M. Du, "The physical layer design of intra-body communication: Model, transmitter and receiver," in Proceedings of the 2011 IEEE International Conference on Consumer Electronics, ICCE 2011, pp. 605-606, Las Vegas, Nev, USA, January 2011.

[12] J. Bae, H. Cho, K. Song, H. Lee, and H.-J. Yoo, “The signal transmission mechanism on the surface of human body for body channel communication," IEEE Transactions on Microwave Theory and Techniques, vol. 60, no. 3, pp. 582-593, 2012.

[13] Ž. Lučev, A. Koričan, and M. Cifrek, "A finite element method study of the current density distribution in a capacitive intrabody communication system," in Proceedings of the 12th Mediterranean Conference on Medical and Biological Engineering and Computing, MEDICON 2010, pp. 422-425, May 2010.

[14] M. A. Callejon, J. Reina-Tosina, D. Naranjo-Hernandez, and L. M. Roa, "Galvanic coupling transmission in intrabody communication: A finite element approach," IEEE Transactions on Biomedical Engineering, vol. 61, no. 3, pp. 775-783, 2014.

[15] K. Hachisuka, T. Takeda, Y. Terauchi, K. Sasaki, H. Hosaka, and K. Itao, "Intra-body data transmission for the personal area network," Microsystem Technologies, vol. 11, no. 8-10, pp. 10201027, 2005.

[16] S. H. Pun, Y. M. Gao, P. Mak, M. I. Vai, and M. Du, "Quasi-static modeling of human limb for intra-body communications with experiments," IEEE Transactions on Information Technology in Biomedicine, vol. 15, no. 6, pp. 870-876, 2011.

[17] Y. Wen, F. Wang, and L. Zhang, "Electric field strength distribution around man model exposed to the radiation of cellular phones," in Proceedings of the 1997 International Symposium on Electromagnetic Compatibility, EMC, pp. 450-454, May 1997.

[18] B. Jakštys, P. Ruzgys, M. Tamošiūnas, and S. Šatkauskas, "Different Cell Viability Assays Reveal Inconsistent Results After Bleomycin Electrotransfer In Vitro," Journal of Membrane Biology, vol. 248, no. 5, pp. 857-863, 2015.

[19] S. Makino, K. Fukuda, S. Miyoshi et al., "Cardiomyocytes can be generated from marrow stromal cells in vitro," Journal of Clinical Investigation, vol. 103, no. 5, pp. 697-705, 1999.

[20] M. Gabi, M. E. Bullen, I. Agarkova et al., "Effects of small pulsed nanocurrents on cell viability in vitro and in vivo: Implications for biomedical electrodes," Biomaterials, vol. 31, no. 33, pp. 8666-8673, 2010.

[21] S. Park, Y. J. Song, H. Boo, and T. D. Chung, "Nanoporous Pt microelectrode for neural stimulation and recording: In vitro characterization," Journal of Physical Chemistry C, vol. 114, no. 19, pp. 8721-8726, 2010.

[22] Y. M. Gao, P. Sio-Hang, and M. Peng-Un, "Development and test of the measurement system of the galvanic coupling type intra-body communication," Journal of Fuzhou University, vol. 39, no. 6, pp. 883-886, 2011.

[23] L. Wan and S. Natarajan, "Experimental verification of variable gain CCII-K circuits and modeling of AD844," in Proceedings of the 1997 29th Southeastern Symposium on IEEE, pp. 168-172, March 1997. 
[24] I. J. A. Evers-Van Gogh, S. Alex, R. Stienstra, A. B. Brenkman, S. Kersten, and E. Kalkhoven, "Electric pulse stimulation of myotubes as an in vitro exercise model: Cell-mediated and noncell-mediated effects," Scientific Reports, vol. 5, article 10944, 2015.

[25] X. Yuan, D. E. Arkonac, P.-H. G. Chao, and G. VunjakNovakovic, "Electrical stimulation enhances cell migration and integrative repair in the meniscus," Scientific Reports, vol. 4, article 3674, 2014.

[26] S. Sun, J. Wise, and M. Cho, "Human fibroblast migration in three-dimensional collagen gel in response to noninvasive electrical stimulus: I. Characterization of induced threedimensional cell movement," Tissue Engineering, vol. 10, no. 910, pp. 1548-1557, 2004.

[27] K.-A. Chang, J. W. Kim, J. A. Kim et al., "Biphasic electrical currents stimulation promotes both proliferation and differentiation of fetal neural stem cells," PLOS ONE, vol. 6, no. 4, article e18738, 2011.

[28] D. Fischer, Y. Li, B. Ahlemeyer, J. Krieglstein, and T. Kissel, "In vitro cytotoxicity testing of polycations: influence of polymer structure on cell viability and hemolysis," Biomaterials, vol. 24, no. 7, pp. 1121-1131, 2003. 


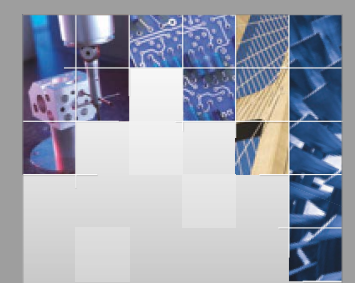

\section{Enfincering}
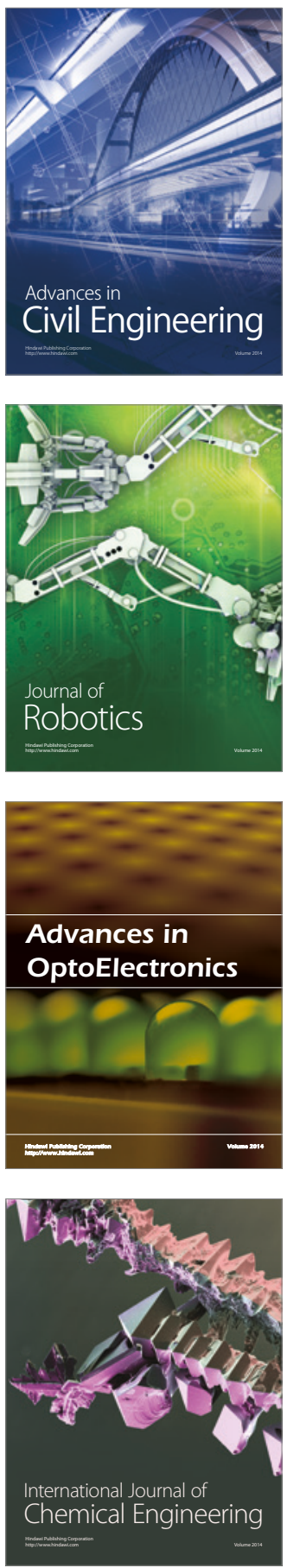

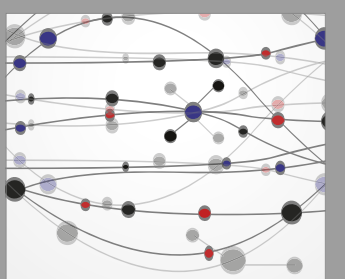

The Scientific World Journal

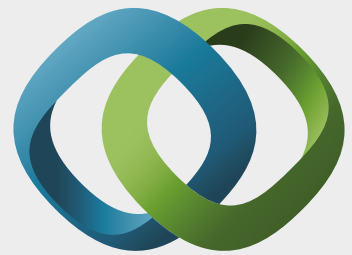

\section{Hindawi}

Submit your manuscripts at

https://www.hindawi.com
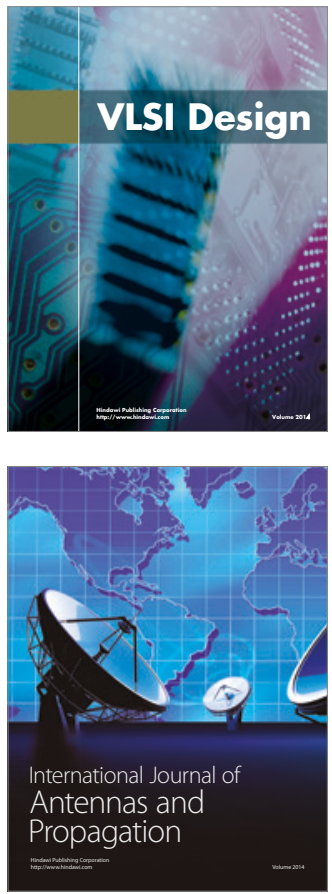

\section{Rotating}

Machinery
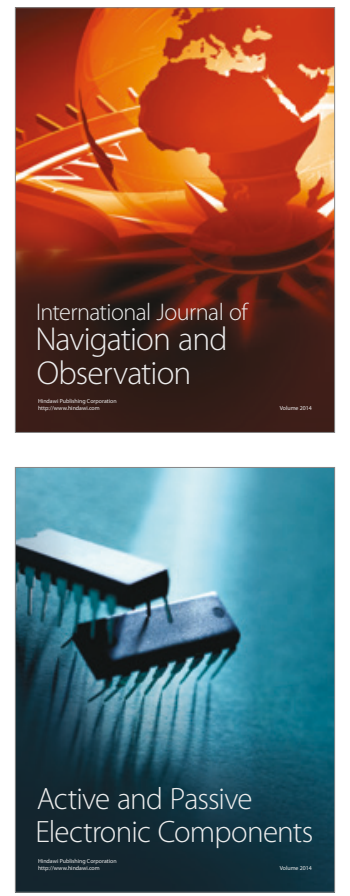
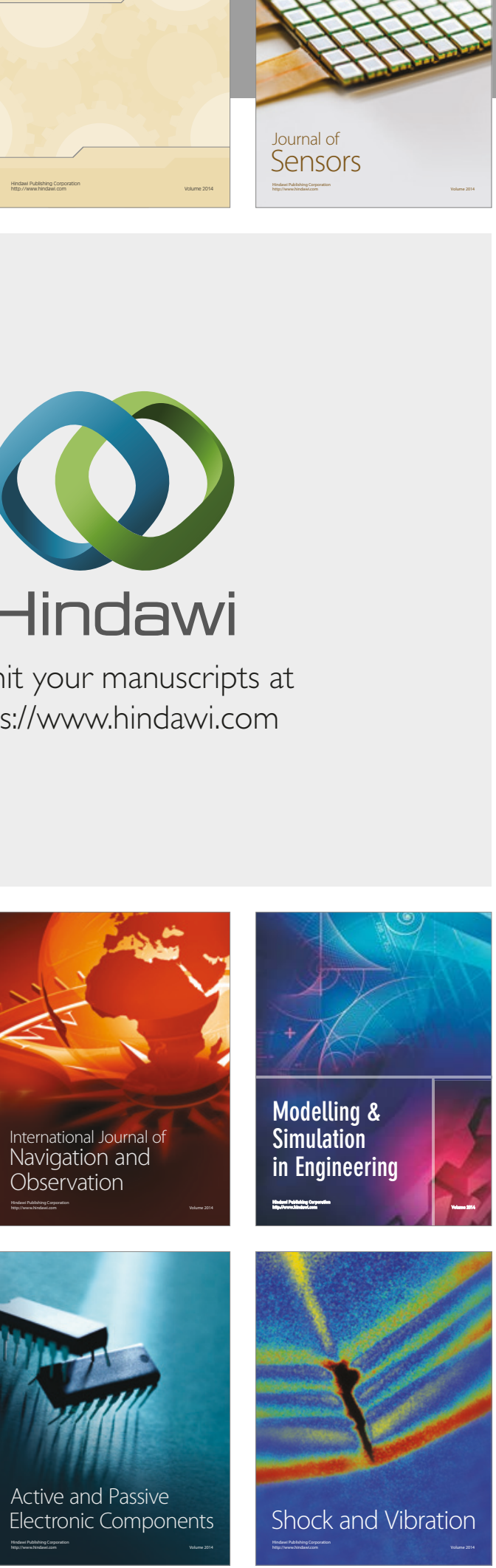
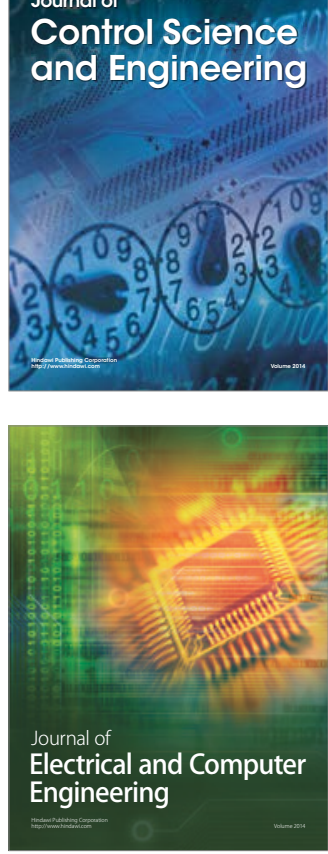

Distributed

Journal of

Control Science

and Engineering
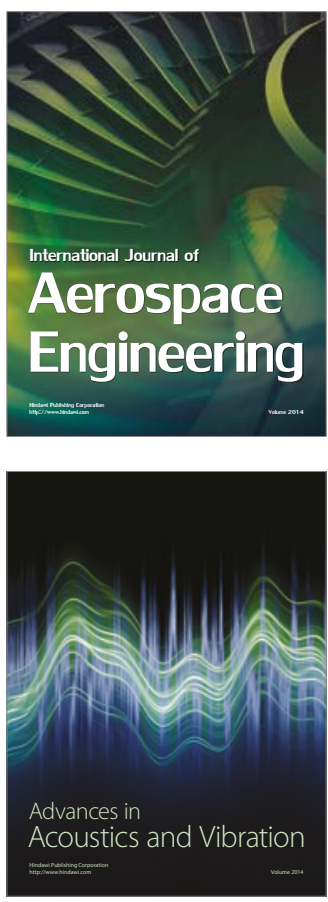

Sensor Networks 